\title{
DUTCH SOCIETY OF LARYNGOLOGY, RHINOLOGY, AND OTOLOGY.
}

Third Annual Heeting, 9th June, I895 (continued). ("Nonatschrift fur Ohrenheilkunde," Feb., I896.)

Dr. Sikke1. Demonstration of a Cast of the Upper Jan' in a Case of Nasal Obstruction.

This was from a boy; aged fourteen, who had always suffered from a nasal obstruction, and from whom a mass of adenoid vegetations had been removed. The cast showed Gothic arching of the hard palate, bending of the alveolar arch in the middle line so that the mesial incisors formed an acute angle, and sinking inwards of the lateral parts. as the result of the pressure of the cheeks during the continuance of the open position of the mouth. The left lateral incisor was absent: the right was only represented by an atrophic residum.

\section{Dr. SIKKEl. Two Cases of Rhinolith.}

The first occurred in a girl aged seventeen, and the kernel was found to consist of a cherry-stone; the second, in one aged twenty-one, contained no foreign body, and was, thereforc, a pure rhinolith.

\section{Dr. SIKKEL. Foreign Body in the Larynx.}

The patient complained of pain arising from a bone which had stuck in his throat whilst he was eating codfish. On the first examination a small bleeding point was seen on the left tonsil; nothing in the larynx. On more thorough examination there was observed on the left side wall, immediately above the pyriform sulcus, a white streak, about three-quarters of a centimètre in length. With the probe it could be made out that the white streak projected and adhered firmly to the wall. It was seized by means of Schroetter's forceps. At first a movement downwards was made, and then a fish-bone 4.5 centimetres in length was extracted.

\section{Dr. SIKKel. A Congenital Fibroma of the Nose.}

This was a soft growth of the size of a canary's egg, occupying in great part the right ala and to some extent the dorsum of the nose of a boy, aged four. At birth it was already of considerable size. It caused considerable projection of the mucous membrane into the lumen of the nose. The tumour was dissected out through a skin incision, the nostril being plugged, and the outer skin wound united by means of stitches. Union took place in a few days. After four months the form of the nose was almost natural. The growth ivas found upon microscopical examination to be a fibroma, with few nuclei and a large quantity of connective tissue.

Prof. H. ZWaARdeMaker. On Toynbee's Otoscope.

The speaker held that as the instrument was generally constructed of materials which conducted sound very badly, the conduction took place 
almost entirely through the air which it contained, and on this account it was advisable that the lumen should be as wide as possible.

In illustration of this he described an experiment, comparing the length of time during which a $\mathrm{C}^{2}$ tuning-fork fixed on a resonating base was heard through a wide and narrow otoscope respectively, the times being sixty-five and fifty-three seconds. It is, therefore, advisable to have the tube of such a calibre as to correspond to that of the external meatus, and, as a rule, a diameter of six millimètres is the most suitable, and this should apply to the earpieces as well as to the india-rubber tube. The instrument should go deeply into the ear, which is only possible when the walls of the tube are thin. The speaker did not think that resonance (sympathetic vibration) came into play in the use of the otoscope. It was a tube closed at both ends by the tympanic membranes, and, therefore, under all circumstances there was an internode at each end and a nodal point at the middle. In the case of an otoscope of $85 \mathrm{~cm}$., the wave length of the proper tone of the instrument would be $170 \mathrm{c.m}$. Its vibration number would be 195 d.v. Such deep tones would hardly ever come under observation during the use of the otoscope. Since in the otoscope as contrasted with the stethoscope the conduction through the walls does not come into play, there is nothing gained by using a binaural instrument.

Dr. BRondGliEst : The opening in the earpiece is always smaller than the diameter of the tube.

Dr. TMAARDEMAKER: The diameter of the earpiece ought to be six millimitres, and the thickness of its walls as slight as possible.

Dr. SIKkEI : Has the speaker measured the duration of vibration of the tuning-fork after slow and quick release of the spring respectively? Lucae's tuning-fork does not have a constant force of stroke.

Dr. ZWA.ARDEMIKER replied that Lucae's tuning-fork was not always constant when you caused it to vibrate for a long time ; but in the experiments which were carried out the mode of operation was identical, so that the comparisons were perfectly reliable, and he was sure that no mechanical or mental differences could affect the result.

Prof. Guye: The tube is ordinarily attached very badly to the earpiece, namely, by means of an intermediate tube which has a lumen of not more than from two to three millimètres. This should not be.

\section{Prof. ZWalnuemakek. On the Degree of Hiaring Power necessary for Telephonists.}

The writer carried out investigations with the ordinary apparatus used for intercommunal purposes. He found that a hearing power of I mètre for whispers allowed of only a few words being heard by the telephone; with $1 \cdot 5$ metres the greater part of a formula; with 2 metres most words were understood, but it was only with 4 mètres that the whole of a sentence could be repeated, and then only with considerable effort; with 6 metres a certain amount of difficulty still remained, and it was only with 7 mètres that a sentence could be quickly and easily followed.

Prof. CiUY: thought it worthy of remark that the public in general 
found the left ear better for telephone use. while the officials at the Central Station made more use of the right one.

Dr. MOLL asked whether investigation had revealed any injurious influence on the hearing.

Dr. ZWAARDENAKER said that none had been observed. A few cases had been mentioned in the literature, but in Holland none such had been recognized among the postal officials; but it was an unquestionable fact that telcphoning, and especially telephone service, entails a great strain on the nervous system, and can give rise to neurasthenia.

\section{Dr. ZWAardenaker. A few Exceptional Auditory Fields.}

In the first instance he showed three "fields" from patients with fracture of the base of the skull, and compared with them cases of labyrinthine deafness from syphilis and from mumps, as also from simple sclerosis, from sclerosis complicated with quinine poisoning, and from labyrinthine deafness resulting from artillery fire. Another was from a case of retinitis pigmentosa--a family affection. There there was a ver: peculiar form of deafness. The lower range of the scale was found on both sides to extend down to $\mathrm{E}^{2}$ (? $\mathrm{E}-\mathrm{s}$ ) (20 d.v.); the upper range to $A^{6}$, and on the left side $A^{6}$.

Between these extremes there was a comparatively even reduction of hearing power. The auditory field was on the right side one-third and on the left side a quarter of the normal.

The case gave the speaker the opportunity of pointing out the analogy between hemeralopia and the paracusis of Willis. In both cases the functional activity was diminished when the degree of light or of sound in the neighbourhood was weakened. On the other hand there was improved function when the source of stimulation was strengthened. In both cases there were disturbances of nutrition at the periphery of the visual or auditory fieid, which in retinitis resulted from the displacement of pigment, and in paracusis from the threatening loss of the upper zones of the scale.

Finally Dr. Zwaardemaker showed two auditory fields from cases of gradually developing labyrinthine deafness. One of these showed a hiatus at that part of the scale which corresponded to the patient's subjective noise. Here. therefore, there occurred complete loss of function, along with an internal source of irritation of considerable duration.

Prof. GUYE considered the comparison of paracusis with hemeralopia particularly interesting, as he was convinced that the former had its origin in the auditory nerve, and had nothing to do with the ossicles of the middle ear.

Prof. GuYe. On a Peiuliar Rotatory Sensation in Labyrinthine Disease which has not hitherto been described.

(Vide JOURNAL OF LARYNGOLOGY, RHINOLOGY, AND OTOLOGY, May, 1896, page 254.)

Dr. SIETHOFT had recently treated a neurasthenic patient whose ears were perfectly normal, and along with migrainous attacks had exactly such rotatory sensations. Another patient, a female, who suffered from 


\section{Rhinology, and Otology.}

slight catarrh of the middle ear, with Ménière's symptoms, described her rotatory sensations in exactly a similar way. She had swelling of the mucous membrane of the posterior extremity of the inferior turbinal. The vertigo disappeared at once on the application of cocaine to the part, and after the removal of the posterior extremity of the turbinal the Ménière's symptoms returned no more. He was disposed in this case to attribute the peculiar form of vertigo to neurasthenic influences rather than to an affection of the labyrinth.

Prof. GUYE said that without doubt in many patients suffering from Ménic̀re's disturbances the trouble was partly of a nervous nature, but we had to be careful lest we should too readily ascribe disturbances to neurasthenia. He thought it probable that in Dr. Siethoft's second patient there was a temporary disturbance (hyperæmia) in the vertical semicircular canal as cause of the vertigo.

Dr. BUtGer thought the description interesting, but the association of it with discases of a semicircular canal, hypothetical on the whole, could only be cleared up in two ways: post-mortem examination and physiological experiment.

Prof. GuYE agrced that there was a hypothetical clement, but he considered it most desirable that such cases should be carefully observed. In his patient one car was completely deaf.

Prof. ZWAARDEMAKER drew attention to two simple means of experiment in such cases : the ordinary piano stool, which Von Kreidl had employed in investigating the labyrinth in deaf mutes, revolving it while the patient was sitting on it, and the ordinary rocking chair.

\section{Dr. AcH Moll. The Treatment of Acutc Diseases of the Accessory Cavities of the Nose.}

In acute catarrh, with swelling of the mucous membrane, there was inevitably a closure of the orifices of the accessory cavities, and, resulting from this, neuralgia, failing of weight, and other discomforts, which crdinarily disappeared without treatment; but, in many cases of rhinitis following influenza, these disturbances persisted. Applications of cocaine or menthol very often produced no effect; and the same was the case with the employment of Politzer's air douche, as recommended by Hartmann. He had seen inflammation of the middle ear follow this treatment, and was inclined to think as the result of it. On the whole, he would reject any method involving compression of the air in the cavities. On the other hand he attributes great value to aspiration; and his method of clearing the cavities was as follows: the mouth and nose are tightly closed, and then the chest is vigorously dilated as in inspiration. In this way there is a diminution of pressure in the accessory cavities and the liquid contents are drawn out. He had proved a lowering of pressure to the extent of fifteen millimètres in a case in which he had made a perforation in the alveolus. He described a severe case in which there was relative opacity on transillumination; and, having cleared away all pus from the nasal cavities, the patient was directed to close the nose and dilate the chest, as above described. Pus was again seen in the nose and the pains were considerably diminished. The patient way 
recommended to repeat the expermment every two hours, and very soon complete recovery took place.

Dr. REINHARDT asked whether Dr. Moll had found serous collections of fluid in the accessory cavities, as lately recorded by Noltemus. He had himself made frequent punctures, but without similar results.

Dr. MoLI had never found a serous exudation; but he aroided making exploratory punctures in acute affections.

Dr. Bulger had seen sevcral cases such as described by Dr. Moll, after influenza, which had recovered spontaneously. He attributed great value to transillumination in such cases. He recommended frequent irrigations through the nose under slight pressure.

Dr. MoLI, agreed that spontaneous recovery could take place: but he had seen cases which remained stationary for several weeks, and only recovered when the aspiration method was practised. The pressure pain disappeared, as a rule, immediately after the aspiration..

Dr. P. Q. BKonidelist. The Treatment of Lupus and Tuberculosis of the Larynx in Advanced Stages.

Founding upon several communicated cases, the writer advised that the treatment under these circumstances should be as vigorous as possible ; and he considered it indicated to remove all diseased tissue by means of the thermal cautery, after the performance of laryngotomy. This treatment should be resorted to when cure is not brought about by endo-laryngeal means. In lupus, which often attacks the epiglottis so severely, this part must be removed completely by means of sub-hyoid pharyngotomy; and, should the interior of the larynx be affected, laryngotomy (thyrotomy) should be carried out shortly after. Finally, he raised the question as to whether, in commencing tuberculosis of the larynx, it was not desirable to remove all diseased tissue by means of laryngo-fissure.

Dundas Grant (Trans. and Abs.).

\section{BRITISH MEDICAL ASSOCIATION. Meeting, July, 1896.}

\section{A ASTRACT OF PAPER.}

The Operation of Thyrotomy. By PHILIP DE SANTI.

The following is a short abstract of the paper I read on the operation of thyrotomy, especially in relation to its efficacy in the treatment of malignant diseasc of the larynx, at the last meeting of the British Medical Association, held in London in August last.

The cases that I have been able to make use of are those that have been in the hands of Mr. Butlin, both in his hospital and private practice, during the last fifteen years. I am much indebted to him for giving me access to his notes.

In the "Lancet" of December, 1894, a paper was published by Dr. Felix Semon, "On the Results of Radical Operation for Malignant Disease 